\title{
Erratum zu: Zerebrale Durchblutungsstörungen: Ischämische Infarkte
}

Peter Ringleb, Roland Veltkamp, Stefan Schwab, Martin Bendszus und Werner Hacke 
Erratum zu:

Kapitel „Zerebrale Durchblutungsstörungen: Ischämische Infarkte“

In: P. Ringleb et al. (Hsrg.), Neurologie,

- DOI 10.1007/978-3-658-22765-4_5

Wir machen darauf aufmerksam, dass die jetzt zur Verfügung gestellte Fassung sich von der zunächst veröffentlichten Fassung unterscheidet. Ursache dafür ist eine Korrektur der Beschriftung in Abbildung 5.38a, b. 